\title{
Learning Management System for Data Structures and Algorithm
}

\author{
Marco Paulo J. Burgos
}

\begin{abstract}
The study addressed the adjustments of academic institutions to online class and modular learning caused by the Covid-19 pandemic. It focused on the development of Learning Management System (LMS) for Data Structures and Algorithms with the main feature that allows students to take modular online learning. The research and development approach includes (i) stages of system development using the Waterfall Method, (ii) level of acceptability of the developed system based on the ISO 25010 standard, (iii) difference in the evaluation of the three groups of respondents, (iv) challenges encountered while using the system, and (v) implementation plan. The respondents chosen through convenience sampling were 60 students, 15 faculty members, and 15 Information Technology (IT) experts. The checklist-format questionnaire was based on the ISO 25010 which determined acceptability using functional suitability, performance efficiency, usability, and reliability criteria. An interview was also conducted to evaluate respondents' experiences using the system. Based on the respondents' evaluation, the developed system was 'acceptable' as reflected by the obtained weighted means. Further results showed no significant difference in the evaluation of the three groups of respondents in terms of functional suitability, performance efficiency, usability, and reliability.
\end{abstract}

Keywords:

learning management system, online education, data structures and algorithms, ISO 25010, Covid-19 pandemic, chatbot

Suggested Citation: Burgos, M.J. (2021). Learning Management System for Data Structures and Algorithm. International Journal of Science, Technology, Engineering and Mathematics, Volume 2, Issue 3, pp. 1- 26.

About the author:

Faculty, City College of Calamba, Philippines. 


\section{Introduction}

LMS is a boundless data framework utilized in numerous higher education institutions to encourage instructive challenges. The framework can be utilized for help in campus courses, courses directed on the Internet, and obviously a combination of these utilizations. It is a web-based innovation used to plan, execute, and evaluate a particular learning measure which furnishes an educator with an approach to make and convey content, screen student participation, and survey student performance.

Due to the effects of Covid-19 pandemic, the education system worldwide had to adjust to the existing new normal. Higher education institutions shifted to online class and modular learning. During this learning mode, the LMS benefits the students in terms of easily accessing the modules and answering examinations and quizzes through online enrichment and module assessment, hence eliminating the physical submission of paper requirements. In addition, students can get the frequently-asked information from the chatbot, an automated answering features of the LMS, which also supplements the communication gap or response time between the students and teachers. This can also be coded with a program in simulator inside the system. For the teachers, the broadcast of announcements is easier and much clearer as opposed to social media and e-learning platforms where messages are in the thread. Moreover, the computation of grades became easier because of the automated save features.

With the benefits of LMS, this study developed and evaluated the use of LMS at a particular higher education institution in the Philippines. It was particularly developed for the subject Data Structures and Algorithms offered in the second year of Bachelor of Science in Information Technology at the School X. This subject provides fundamental information on standard information portrayal and calculations to tackle processing challenges effectively (as for space prerequisites and time complexity nature of calculation). This covers the accompanying Stacks, Queues, Trees, Graphs, Maps and Sets, careful conversation of arranging and looking through calculations and hashing secured. The hypothetical hours are through the lecture rooms while the practical hours are in the laboratory (a study hall furnished with computers for every student). Programming information is essential for the utilization of specific technology students will use throughout their scholastic years. This subject has lecture time of two hours composed of 
weekly hypothetical exercises utilizing customary techniques and three hours of hands-on practical exercises.

According to Lokare and Jadhav (2016), the subject Data Structures and Algorithms has noticeable significance for higher studies and placement in programming enterprises. Thus, better comprehension of this course brings about fruitful professional formation. It has been observed that the usual teaching and learning procedure is not helping students to enhance their learnings leading to poor comprehension and performance in higher studies.

\section{Literature Review}

\subsection{Development of LMS through Waterfall Method}

According to Andersson (2019), LMS is a product application or web-based innovation used to plan, execute, and evaluate a particular learning measure. Ordinarily, it furnishes an educator with an approach to make and convey content, screen student participation, and survey student performance. It may likewise furnish students with the capacity to utilize intuitive highlights such as threaded conversations, video meetings, and conversation forums. When building up a data framework, various models can be utilized as help support for the development. The most customary methodology is the Waterfall Model of the Systems Development Life Cycle (SDLC).

According to Rainer, Prince, and Cegielski (2015), the model illustrates the advancement into six stages: requirements analysis, system design, implementation, testing/verification, deployment, and maintenance. The various stages have clear characterized tasks, and if challenges happen in one phase, the researcher needs to return to past stages to tackle the challenge. The (1) requirements analysis stage recognizes the genuine needs, utilizes a feasibility study, which looks at technical, economical, and social perspectives all together. Conversations on the different business challenges that the advancement should tackle, happen in the framework investigation stage, subsequently assembling data pretty much all the necessities and a final output of a bunch of framework prerequisites. In the (2) system design stage, the framework is set up and particulars of the arrangement is endorsed, where also the programming and testing happens. In the (3) implementation stage, the LMS is developed. In the (4) testing phase, the new framework is in a pilot adaptation to the 
groups of respondents while the (5) deployment phase which alludes to the actual implementation of the system to the benefactors' usage, where in this study pertains to the system of the Department of the Computer Education of the School X. The last stage is the (6) maintenance of the new framework, where the identified challenges from the uploaded web application of LMS for Data Structures and Algorithms are addressed.

In a study by Muhard, et al. (2020), the Waterfall Model was utilized in designing a web-based LMS. It has been depicted how the plan of the framework in the advancement of LMS on this site. Subsequently, it was inferred that the teaching and learning process in a website permitted students to have materials downloaded straight through the site. Thu, the degree of connection among teachers and students increased the online correspondence media, where students and teachers can associate with one another through this LMS application.

\subsection{Software Evaluation and Quality Assurance}

According to Krouska, Troussas and Virvou (2019), utilizing ISO 25010 international standard for the assessment of any software is fair and dependable. It also depends on the proper standard attributes to access the quality of educational software. The audit targets the indication of advancement of master frameworks in e-learning because of the rise of interpersonal interaction and the commitment of its qualities to the educational process. The development of high quality software is imperative because the learning networks nowadays are PC-educated and have rising expectations for the systems being used.

E-learning is generally alluded to the use of Information and Communications Technology (ICT) for conveying instructive educational programs. It is quickly developing because of the wide Internet use, the abilities of ICT to help the learning cycle and the diminished expense of online training. It gives electronic guidance through which students can get to online course materials. A conventional methodology of e-learning is the LMS. It is an amazing instructive programming for overseeing course substance and students and offers online mastering, appraisal and 
preparing asset and understudy management. Not only to convey course content, it gives a more student-focused guidance.

By utilizing an ISO-based model, the dependability of framework assessment is expanded as it depends on standard attributes legitimate to survey the nature of programming items or the potential quality being used. Additionally, this sort of assessment can demonstrate that a framework meets all the requirements and gives clients the affirmation of item quality. ISO 25010 is a broadly acknowledged and very much perceived quality standard that has been applied to an assortment of programming item assessment cases. Notwithstanding, there are just couple of uses of this model to the e-learning conditions.

\subsection{Challenges of the LMS}

According to Al-Samarraie and Saeed (2018), current innovative advances assume a critical function in the improvement of formal schooling through numerous methods of learning conveyance and correspondence that can easily meet the instructional requirements. For instance, Malik, Abid, Kalaichelvi, and Bhatti (2018) argued that although there has been improvement in the instructional learning cycle of software engineering and data innovation, these could still not deliver the necessary results. It is critical to build up a modern educational plan of software engineering and IT which satisfies the ongoing prerequisites of the subjects. State-of-the-art equipment and programming-prepared computer laboratories are important for software engineering and data innovation. Meanwhile, appropriate and organized computer lay-out is needed to likely control the computer frameworks. Moreover, e-learning labs should be encouraged independently.

According to Kocaleva, Stojanovic, and Zdravev (2015) the recent years show an increasing trend in the utilization of ICT in the field of education. Thus, educational institutions implement continuing professional development related to the use of ICT in teaching and learning. Although the utilization of e-learning is deemed vital for instruction, the college academic staff attribute the seldom use of e-learning to absence of adequate time. 


\subsection{Implementation of LMS in Higher Education}

According to Abdulazeez and Zeebaree (2018), to adapt the e-learning framework, the plan and execution of LMS must also be prepared. The LMS works towards an e-learning framework for building up the association and conveyance of teaching materials, overseeing and administrating assets, and following learning exercises and results. Its parts should encourage the consistency of conveyance, furnish the instructive establishment with integral assets for educational plan improvement, correspondence between staff, coordinated effort, scheduling and task the mechanization. However, the plan and usage of such framework is certainly not a simple assignment. For instance, outsourced LMS for enlistment and internet instructional classes maybe critical to be modified according to the instructors and students prerequisites.

Tarus, Gichoya, and Muumbo (2015) argued that the implementation of LMS in colleges should be seen as a feature of instructive change. For e-learning to be productive and powerful, a lot of care and consideration needs to go into its usage. There are various difficulties to conquer while executing e-learning in colleges. Zeroing-in preparing on the innovative highlights of the e-learning framework is just the initial step to progress; the genuine test is preparing for changes to teaching method. E-learning's prosperity lays on the principal prerequisite that teachers and understudies have satisfactory specialized abilities to utilize e-learning instruments successfully. These difficulties range from innovative, hierarchical and instructive difficulties. Colleges that are intending to actualize e-learning in their organizations should be set up to react to the difficulties that are probably going to emerge over the span of usage. In the event that e-learning is to be effectively embraced in a school, educators and head instructors should be associated with the dynamic cycles. Administration and backing from senior administration are distinguished as basic variables for fruitful usage. For e-learning to prevail, it needs to expand on another significant column: the presence of framework, alongside network. Non-industrial nations actually face a ton of difficulties while actualizing e-learning which requires progressed level of innovative foundation and weighty speculation of assets particularly at the underlying stages.

According to Banimahendra and Santoso (2017), assessment is an action identified

with data collection-related usability of an item, including a gathering of clients in a particular setting. While the usability evaluation is a progression of strategies performed to 
gather information identified with the connection between clients with programming items, to discover how enormous the commitment of a product in assisting clients with accomplishing objectives. Along these lines, in the end, the after-effects of the usability assessment can be utilized to anticipate the accomplishment of an item when it is dispatched.

\section{Methodology}

This study utilized the developmental research through descriptive design in developing a framework following the Waterfall Method.

Part of gathering information is about the current and existing methods of teaching for Data Structures and Algorithms in School X. This assessed the current situation to gather necessary information and data for further understanding and investigation.

\section{Figure 1}

The Waterfall Model

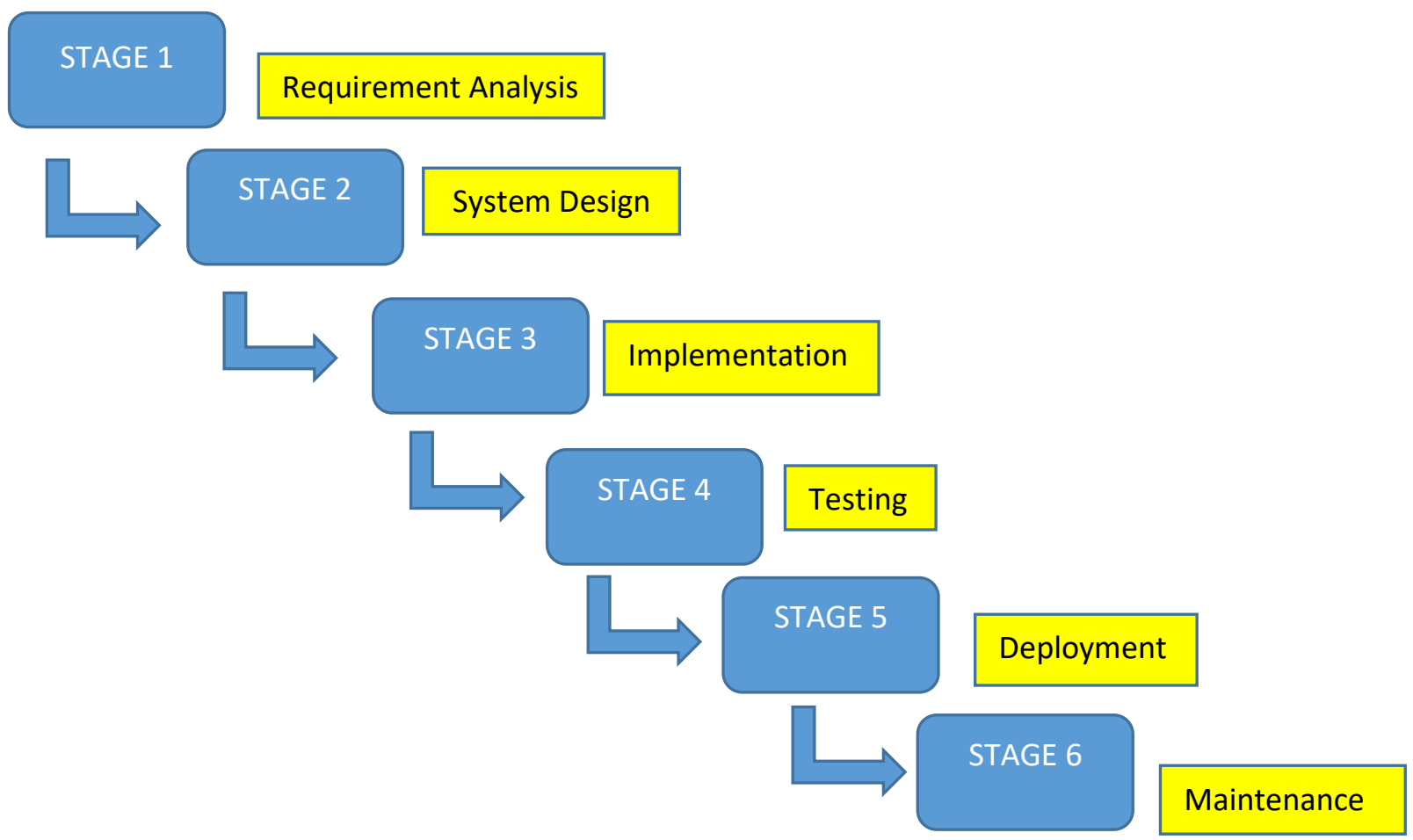

Source: Introduction to Information Systems. 5th ed, by Rainer, Prince, \& Cegielski, 2015, John Wiley \& Sons Singapore Pte. Ltd.

The Waterfall Method was utilized in creating the proposed system. Waterfall formulations are usually used in computer program improvement which reacts to 
irresoluteness changes. The model illustrates the advancement into six stages: requirements analysis, system design, implementation, testing, deployment, and maintenance. These stages correspond as to how the first research objective was answered.

The population frame for this study were IT experts, faculty members, and former students enrolled in the subject Data Structures and Algorithms at the School X during the current semester. As a sampling scheme, the study used the convenience sampling method. It is an exemplification of non-random/non-probability sampling wherein sample individuals from the reference populace that meet a certain level of functional standards are incorporated for study purpose. Considering the present pandemic situation where everyone was required to stay at home, the study had to select the experts, teachers, and students who have active internet connection at home. The samples selected were then subjected to the new treatment method, utilizing the LMS.

The total respondents were ninety (90), composed of sixty (60) students, fifteen (15) faculty members, and fifteen (15) IT experts. The respondents were the former students enrolled in the subject Data Structures and Algorithms at the School X, faculty members who were teaching or have taught the subject, and IT professionals composed of experts from the industry and the IT administrator of Bachelor of Science in Information Technology in School $\mathrm{X}$. The respondents were interviewed to gain understanding on their needs and to prove that the proposed system was needed for the school. A set of carefully prepared and logically ordered questions were used to collect data.

The researcher utilized a set of instruments in gathering the vital data. These were the adopted questionnaire, interview guide, and document analysis. The adopted checklist questionnaire in a Google Form was the standardized assessment tool based on ISO 25010. This is a significant tool to evaluate the respondents' perspectives on the current system or the new framework. The said tool was founded on ISO 25010:2011 standard for software development designed to evaluate and to determine the level of acceptability of LMS for Data Structures and Algorithms with respect to functional suitability, performance efficiency, usability, and reliability. The questionnaire was answered by the students, faculty, and IT experts. The Likert scale was used to determine the level of acceptability which answered the second research objective. 
The interview guide was utilized to determine the challenges experienced by the respondents during the assessment, different remarks, and recommendations that maybe considered for the improvement of the system. An interview was conducted through online messaging because of the limitation on the face-to-face meeting. The respondents were asked on the considerations in utilizing the developed program. The meeting principally comprised of the inquiries with respect to the usefulness of the created framework such as the adjustments in the functionalities and the challenges experienced in using the program. These data correspond to the fourth research objective.

There were documents analyzed which include outcome-based teaching and learning (OBTL) and the subject modules for Data Structures and Algorithms. Meanwhile, the ANOVA was used to answer the third research objective on the significant difference in the evaluation of the three groups of respondents. For the data analysis, Microsoft Excel and SPSS programs were used. The statistical techniques utilized were Weighted Mean and OneWay Analysis of Variance (ANOVA).

\section{Results and Discussion}

The waterfall methodology comprised of the following phases: requirements analysis, system design, implementation, testing, deployment, and maintenance phases as shown in Figure 1.

The E-Learning Platform denotes the significance of the theoretical framework to the study as it represents the overall principle of the operation of an e-learning LMS platform for Data Structures and Algorithms by introducing the key highlights related with the primary benefactors: students, teachers, and administrators. 
Figure 2

The E-Learning Platform

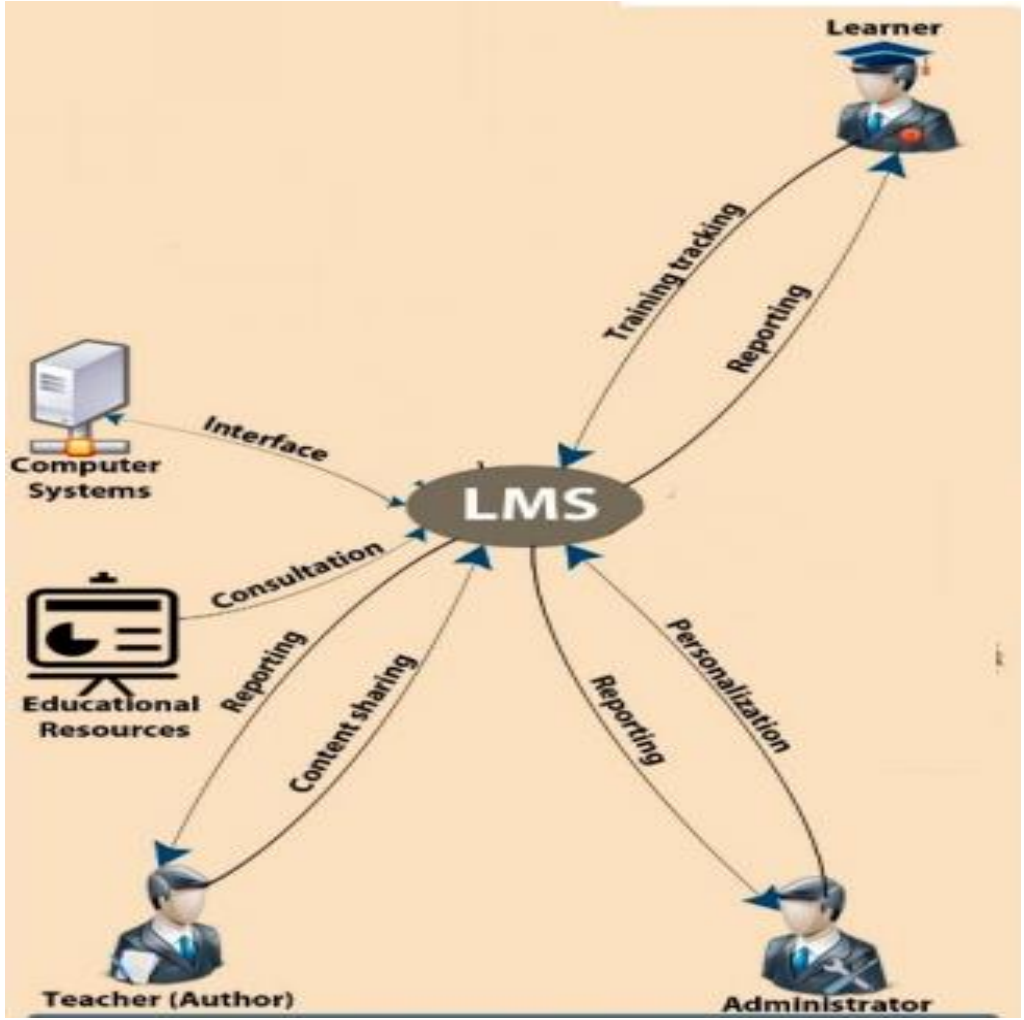

Source: Educational Modeling of a LMS by Ouadoud, Chkouri, and Nejjari (2018)

As shown in Figure 3, the flowchart reflects the process of LMS development for Data Structures and Algorithms. All users are prompted to the login page of the system which serves as the security. Depending on the users' profile, the system has different menu features based on the user's role in the LMS. For example, the administrator has control of all the accounts. The Module \& Assessment is saved to the cloud server where the teachers and students basically interact. The chatbot was added to help teachers and students adapt the system and learn the subject Data Structures and Algorithms. 
Figure 3

LMS Flow Chart for Data Structures and Algorithms

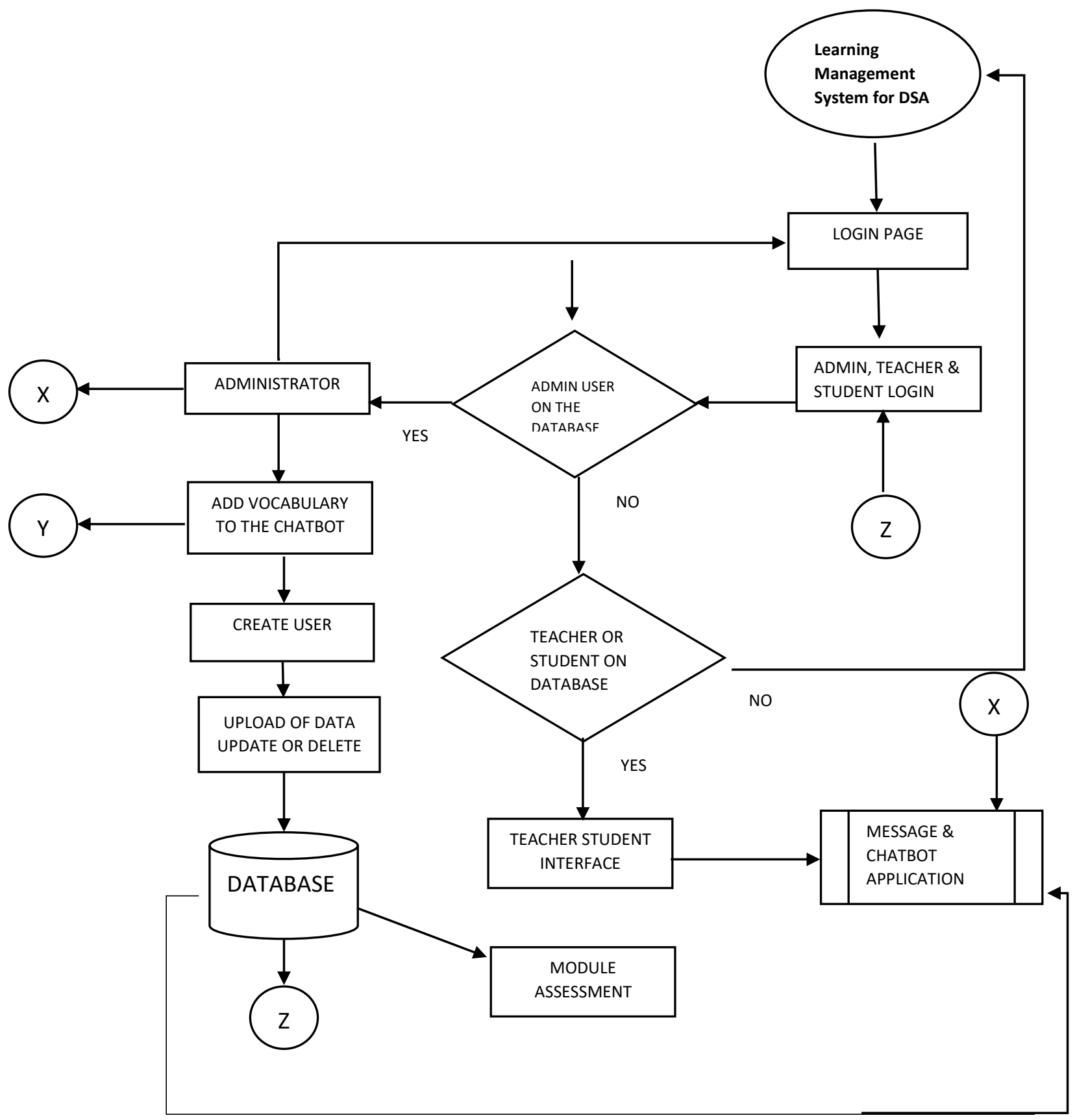

\subsection{Level of LMS Acceptability}

The LMS for Data Structures and Algorithms was evaluated by the three groups of respondents - the students, faculty members, and IT experts. Table 1 shows the functional suitability as perceived by the students, faculty members, and IT experts. 
Table 1

The Functional Suitability of the LMS

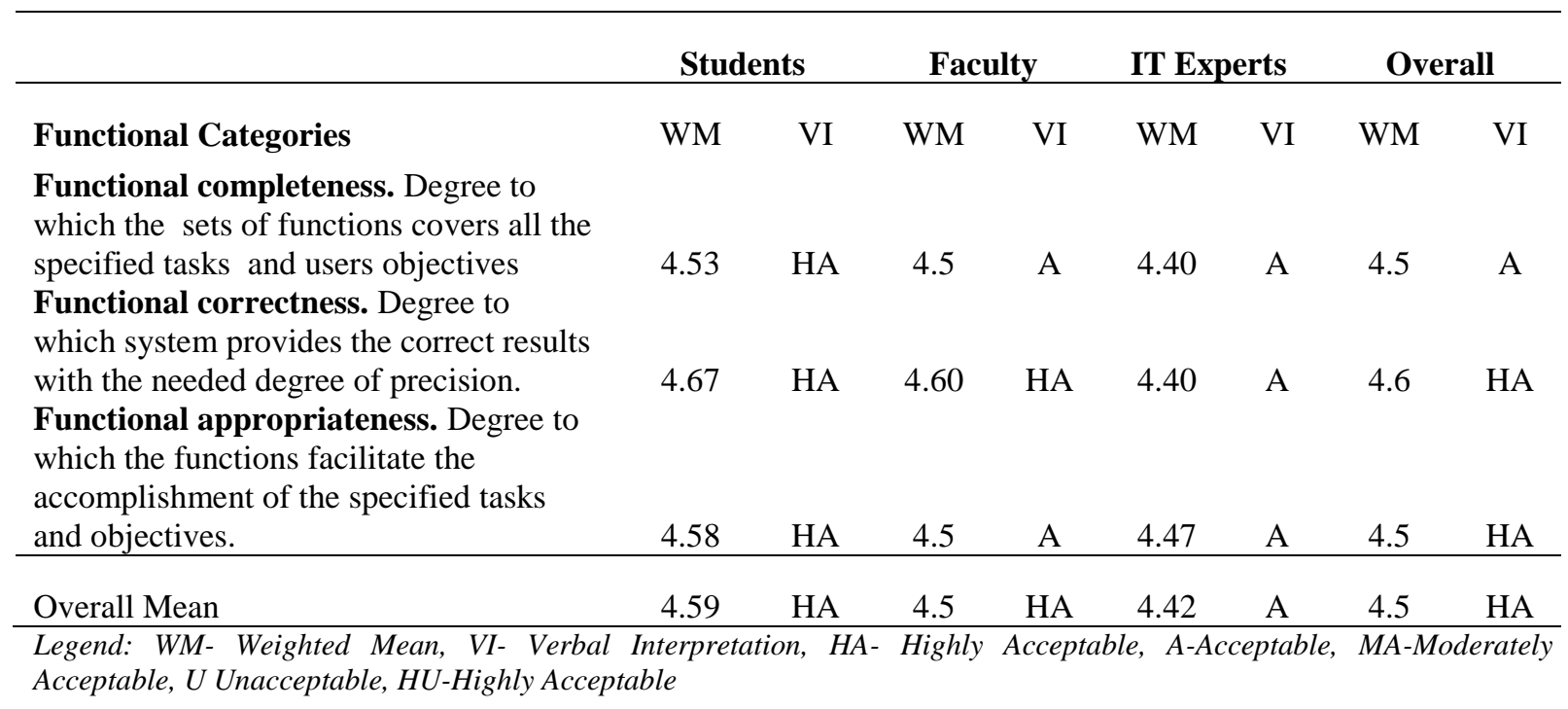

The overall mean gathered from the three functional categories was 4.51. This indicates that in terms of functionality, the respondents perceived the LMS as highly acceptable. The students perceived that the system operates according to its desired functionality as the calculated mean is 4.59 which is interpreted as 'highly acceptable'. Additionally, the faculty members has the same 'highly acceptable' perception of functional suitability with a mean of 4.51. Moreover, the IT experts perceived that the developed system was able to provide its intended function with a mean of 4.42 which is acceptable. Functional suitability is used to determine if the product provides functionalities that meet all the stated or implicit requirements when used under specific conditions. According to ISO 25010, it is a collection of characteristics that lean on the beingness of a set of purposes and their nominative characteristics. The purposes are those that fulfill explicit or implicit conditions.

Table 2 shows the evaluation of the LMS in relation to performance efficiency. It indicates that the developed system is interpreted as 'acceptable' with an overall mean of 4.32. Henceforth, the respondents reckoned that the LMS for Data Structures and Algorithms is efficient to use and it meets the requirements. 
Table 2

The Performance Efficiency of the LMS

\begin{tabular}{|c|c|c|c|c|c|c|c|c|}
\hline \multirow[b]{2}{*}{ Functional Categories } & \multicolumn{2}{|c|}{ Students } & \multicolumn{2}{|c|}{ Faculty } & \multicolumn{2}{|c|}{ IT Experts } & \multicolumn{2}{|c|}{ Overall } \\
\hline & WM & VI & WM & VI & WM & VI & WM & VI \\
\hline $\begin{array}{l}\text { Time Behavior. Degree to which the } \\
\text { response and processing times and } \\
\text { throughput rates of the system, when } \\
\text { performing its functions, meet }\end{array}$ & & & & & & & & \\
\hline $\begin{array}{l}\text { requirements. } \\
\text { Resource utilizations. Degree to which } \\
\text { the amounts and types of resources used } \\
\text { by the system, when performing its }\end{array}$ & 4. 60 & HA & 4.3 & A & 4.40 & A & 4.44 & A \\
\hline functions, meet requirements. & 4.42 & A & 4.40 & A & 4.27 & A & 4.36 & A \\
\hline
\end{tabular}

Capacity. Degree to which the maximum limits of the system parameter meet the requirements.

$\begin{array}{cccccccc}4.37 & \mathrm{~A} & 4.2 & \mathrm{~A} & 4.33 & \mathrm{~A} & 4.32 & \mathrm{~A} \\ 4.46 & \mathrm{~A} & 4.3 & \mathrm{~A} & 4.33 & \mathrm{~A} & 4.37 & \mathrm{~A} \\ \begin{array}{l}\text { Interpretation, } \\ \text { able }\end{array} & \text { HA- } & \text { Highly } & \text { Acceptable, } & \text { A-Acceptable, } & \text { MA-Moderately }\end{array}$

The students evaluated that the developed system was able to meet the requirements in time behavior, in utilizing its resources when performing tasks and it met its maximum limit of the system parameter required. The faculty members perceived that the developed system was able to perform efficiently with a mean of 4.23. Lastly, the IT experts perceived the developed system as acceptable with a 4.33 mean for all categories.

As for the interview organized after the evaluation, the respondents observed that the system was able to act in response to requests in an apt and judicious manner. It was also derived from the interview that the system was able to serve several users at the any one particular point in time. Performance efficiency is dictated by how an application carries on under expressed condition. It influences consumer loyalty, labor force profitability, application adaptability, reaction time debasement, and insufficient utilization of preparing or capacity assets. Despite the fact that the general performance efficiency of an application is wanted, the individual parts execution of an application influences the general presentation proficiency of the created framework just as the interconnectivity of these individual segments. According to ISO 25010, it is a collection of characteristics that lean on the connectedness between the level of performance of the product and the mensuration of possession utilized, under explicit stipulation. 
International Journal of Science, Technology, Engineering and Mathematics, Volume 2 Issue 3

The table 3 presents the assessment on the usability of the system.

Table 3

The LMS Usability

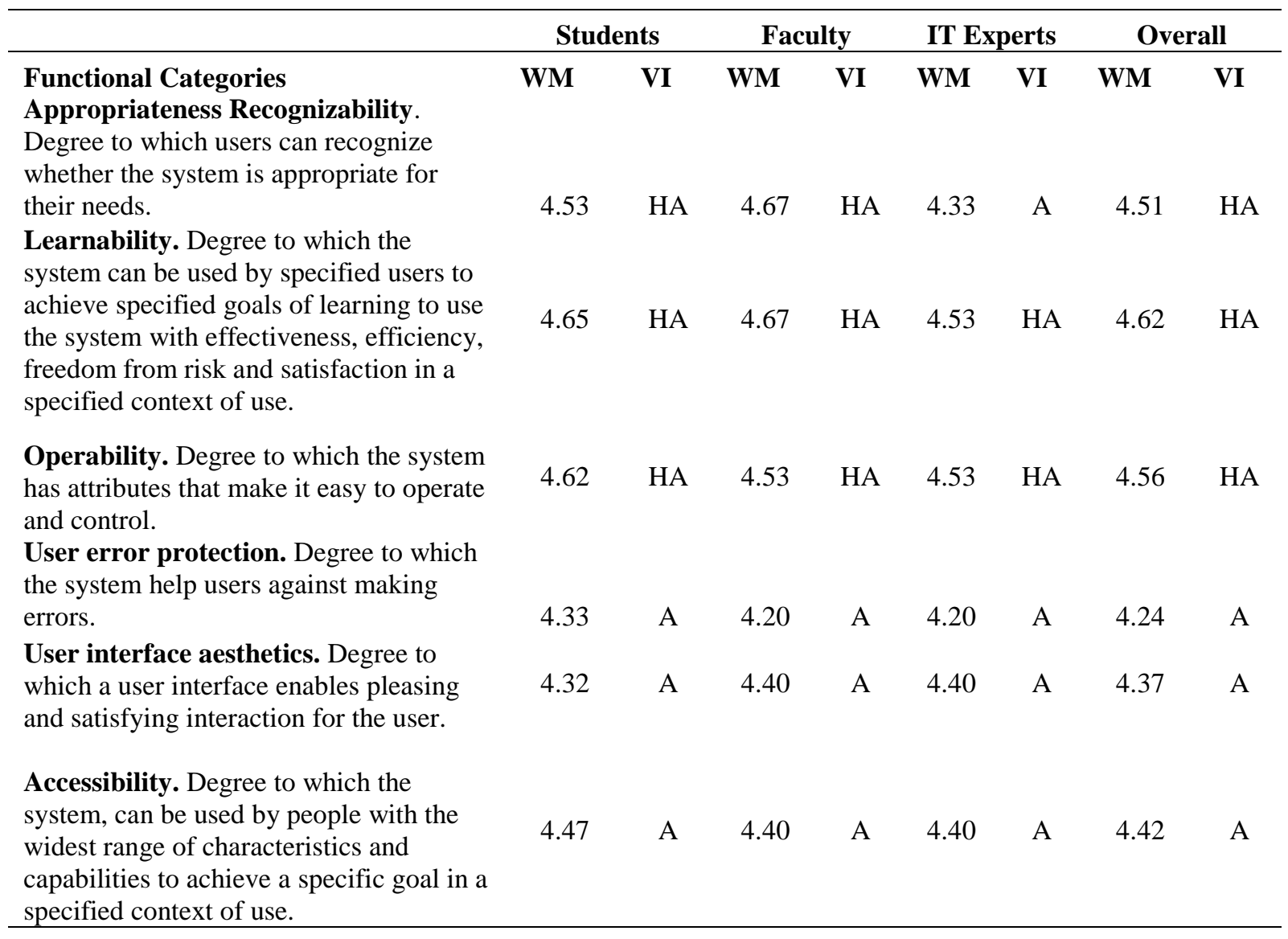

$\begin{array}{lllllllll}\text { Overall Mean } & 4.49 & \text { A } & 4.48 & \text { A } & 4.40 & \text { A } & 4.45 & \text { A }\end{array}$

Legend: WM- Weighted Mean, VI- Verbal Interpretation, HA- Highly Acceptable, A-Acceptable, MA-Moderately Acceptable, U Unacceptable, HU-Highly Acceptable

In terms of suitability, users recognize that the LMS is acceptable as the overall mean from the three groups of respondents for the six usability categories is 4.45 . Respondents reiterated during the interview that the framework is genuinely simple to use without specialized foundation as well as it is good for a wide range of clients.

The students recognized that the system is easy to use and always accessible receiving a mean of 4.49 which is 'acceptable'. Meanwhile, the faculty members acclaimed that the system operates according to their usage requirements with a mean of 4.48. Lastly, the IT experts identified that the system is appropriate for their usage requirements with a mean of 4.40. Usability refers to the ease of usage and the learnability of the created framework. It 
additionally alludes to the time distributed to play out an undertaking, blunders made and the span it takes for the client to be equipped in utilizing the framework. According to ISO 25010, it is the amount a component or model can be used by known clients to do bespoken goals with practicality, competency and consummation in a predefined background of utilization.

Table 4 reports the assessment of the LMS reliability.

Table 4

The Reliability of the LMS

\begin{tabular}{|c|c|c|c|c|c|c|c|c|}
\hline \multirow[b]{3}{*}{$\begin{array}{l}\text { Functional Categories } \\
\text { Maturity. Degree to which the system, } \\
\text { product or component meets the needs } \\
\text { for the reliability under normal } \\
\text { operation. }\end{array}$} & \multicolumn{2}{|c|}{ Students } & \multicolumn{2}{|c|}{ Faculty } & \multicolumn{2}{|c|}{ IT Experts } & \multicolumn{2}{|c|}{ Overall } \\
\hline & WM & VI & WM & VI & WM & VI & WM & VI \\
\hline & 4.52 & HA & 4.33 & A & 4.33 & A & 4.39 & A \\
\hline $\begin{array}{l}\text { Availability. Degree to which a product } \\
\text { or system is operational and accessible } \\
\text { when required for use }\end{array}$ & 4.60 & HA & 4.53 & HA & 4.53 & HA & 4.56 & HA \\
\hline $\begin{array}{l}\text { Fault Tolerance. Degree to which the } \\
\text { system operates as intended despite the } \\
\text { presence of the hardware or software }\end{array}$ & & & & & & & & \\
\hline $\begin{array}{l}\text { faults. } \\
\text { Recoverability. Degree to which the }\end{array}$ & 4.17 & A & 4.27 & A & 4.27 & A & 4.23 & A \\
\hline $\begin{array}{l}\text { system can recover the data directly } \\
\text { affected and re-establish the desired } \\
\text { state of the system }\end{array}$ & 4.37 & A & 4.40 & A & 4.40 & A & 4.39 & A \\
\hline Overall Mean & 4.41 & A & 4.38 & A & 4.38 & A & 4.39 & A \\
\hline
\end{tabular}

The respondents appraised the LMS as 'acceptable' in which it worked dependably under ordinary working conditions and updates with a weighted mean of 4.39. The students remarked that the program addressed the challenges for reliability since it accumulated a mean of 4.41. The faculty members and the IT experts assessed the system with an acceptable reliability (WM - 4.38).

The interview revealed that the framework is accessible and has the option to offer assistance whenever the user requires. The reliability of a product framework is a proportion of how well clients are furnished with the services required. It is characterized as the likelihood of mistake free activity for a particular time in a particular climate and for a 
particular reason. According to ISO 25010, it is a collection of constructs that lean on the ability of the program to keep its steady execution under declared premises for an expressed time period.

\subsection{The Significant Difference in the Three Groups of Responses}

Table 5

The Statistical Analysis of the Significant Difference

\begin{tabular}{|c|c|c|c|c|c|c|c|c|}
\hline Variables & $\begin{array}{l}\text { Source of } \\
\text { Variation } \\
\end{array}$ & $\begin{array}{l}\text { Sum of } \\
\text { Squares }\end{array}$ & Df & $\begin{array}{l}\text { Mean } \\
\text { Square }\end{array}$ & $\mathbf{F}$ & Sig. & Decision & Remarks \\
\hline \multirow[t]{3}{*}{$\begin{array}{l}\text { Functional } \\
\text { Suitability }\end{array}$} & $\begin{array}{l}\text { Between } \\
\text { Groups }\end{array}$ & 0.386 & 2 & 0.193 & 0.783 & 0.460 & \multirow{3}{*}{$\begin{array}{l}\text { Failed to } \\
\text { reject null } \\
\text { hypothesis }\end{array}$} & \multirow{3}{*}{$\begin{array}{l}\text { No Significant } \\
\text { difference among } \\
\text { the means of } 3 \\
\text { groups }\end{array}$} \\
\hline & $\begin{array}{l}\text { Within } \\
\text { Groups }\end{array}$ & 21.428 & 87 & 0.246 & & & & \\
\hline & Total & 21.814 & 89 & & & & & \\
\hline \multirow[t]{3}{*}{$\begin{array}{l}\text { Performanc } \\
\text { e Efficiency }\end{array}$} & $\begin{array}{l}\text { Between } \\
\text { Groups }\end{array}$ & 0.327 & 2 & 0.163 & 0.546 & 0.581 & \multirow{3}{*}{$\begin{array}{l}\text { Failed to } \\
\text { reject null } \\
\text { hypothesis }\end{array}$} & \multirow{3}{*}{$\begin{array}{l}\text { No Significant } \\
\text { difference among } \\
\text { the means of } 3 \\
\text { groups }\end{array}$} \\
\hline & $\begin{array}{l}\text { Within } \\
\text { Groups }\end{array}$ & 26.020 & 87 & 0.299 & & & & \\
\hline & Total & 26.347 & 89 & & & & & \\
\hline \multirow[t]{3}{*}{ Usability } & $\begin{array}{l}\text { Between } \\
\text { Groups }\end{array}$ & 0.090 & 2 & 0.045 & 0.219 & 0.803 & \multirow{3}{*}{$\begin{array}{l}\text { Failed to } \\
\text { reject null } \\
\text { hypothesis }\end{array}$} & \multirow{3}{*}{$\begin{array}{l}\text { No Significant } \\
\text { difference among } \\
\text { the means of } 3 \\
\text { groups }\end{array}$} \\
\hline & $\begin{array}{l}\text { Within } \\
\text { Groups }\end{array}$ & 17.831 & 87 & 0.205 & & & & \\
\hline & Total & 17.921 & 89 & & & & & \\
\hline \multirow[t]{3}{*}{ Reliability } & $\begin{array}{l}\text { Between } \\
\text { Groups }\end{array}$ & 0.017 & 2 & 0.009 & 0.032 & 0.968 & \multirow{3}{*}{$\begin{array}{l}\text { Failed to } \\
\text { reject null } \\
\text { hypothesis }\end{array}$} & \multirow{3}{*}{$\begin{array}{l}\text { No Significant } \\
\text { difference among } \\
\text { the means of } 3 \\
\text { groups }\end{array}$} \\
\hline & $\begin{array}{l}\text { Within } \\
\text { Groups }\end{array}$ & 22.945 & 87 & 0.264 & & & & \\
\hline & Total & 22.962 & 89 & & & & & \\
\hline
\end{tabular}

The computed ANOVA presented in Table 5 shows no significant difference in the assessments of the three groups of respondents in terms of functionality, efficiency, usability, and reliability. This result is based on the computed F-value significance level of the four categories $(0.460,0.581,0.803$, and 0.968$)$ which are all greater than $\alpha 0.05$ value. This eventually accepts the null hypothesis that there is similarity in the assessments of the groups of respondents. Generally, the assessment implies that the proposed system meets the functionality, efficiency, usability, and reliability requirements of the respondents.

\subsection{Challenges Encountered on the Use of LMS}

\subsubsection{Challenges in the development of LMS using Waterfall}


Part of the Waterfall Method is the System Design Stage which provides several feedbacks specifically the color of the login page and interface as illustrated in Figure 4. Another issue brought up was the customization of the display picture of the user. Ten (10) out of the fifteen (15) faculty members commented that the interface is not matched with the color of the login page.

Figure 4

The LMS Administrator Account in Design and Color Before and After Enhancement

\section{Alpha Version}

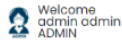
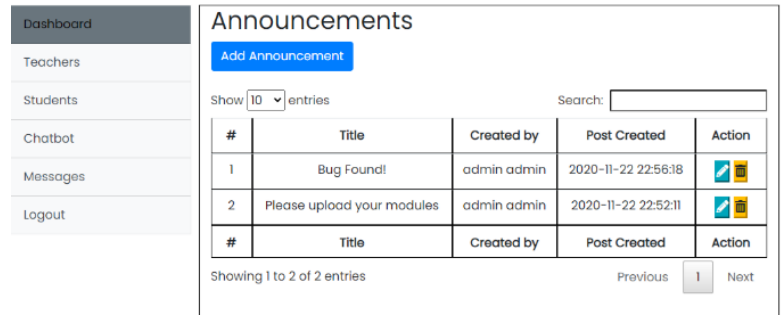

Data Structure and Algorithm

\section{Beta Version}

\section{2.}

Data Structures and Algorithms
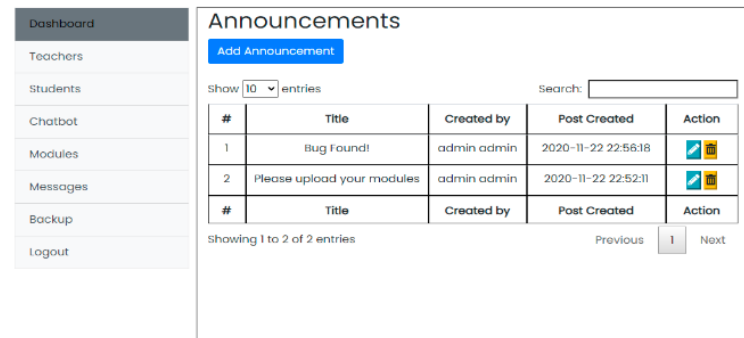

The color was blended to that of the header from the suggested part of the web application and matched it with blue gradient.

Another comment made by forty-five (45) out of sixty (60) students was on the display that was too plain and unchangeable.

Figure 5

The LMS Student Account Change Display Picture Features Before and After Enhancement

\section{Alpha Version}

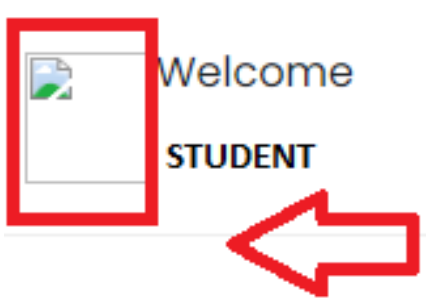

\section{Beta Version}

\section{$\therefore$ Data Structures and Algorithms}

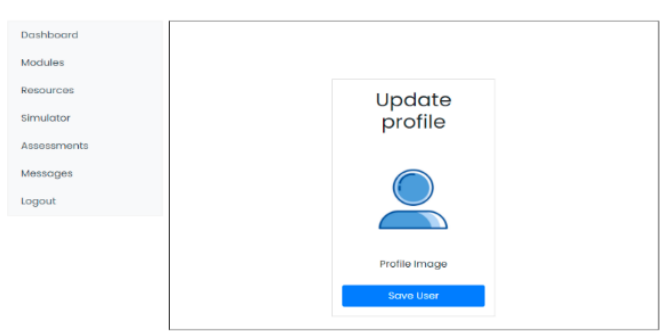


The files were re-encoded by adding update profile picture page for the students' photos.

\subsubsection{Challenges on the level of LMS acceptability based on ISO 25010}

The challenges brought up by the IT experts in this aspect falls under the functional suitability. The ten (10) out of fifteen (15) IT experts suggested to add an import feature in the system which was easily resolved by adding an upload button beside the add student button. It resulted to less downtime in the parts of the administrator and teacher.

\section{Figure 6}

The LMS Administrator Account Adding CSV or EXCEL Import Files Before and After Enhancement

\section{Alpha Version}

\section{List of Students}

\section{Add Student}

Show $10 \vee$ entries

\section{Beta Version}

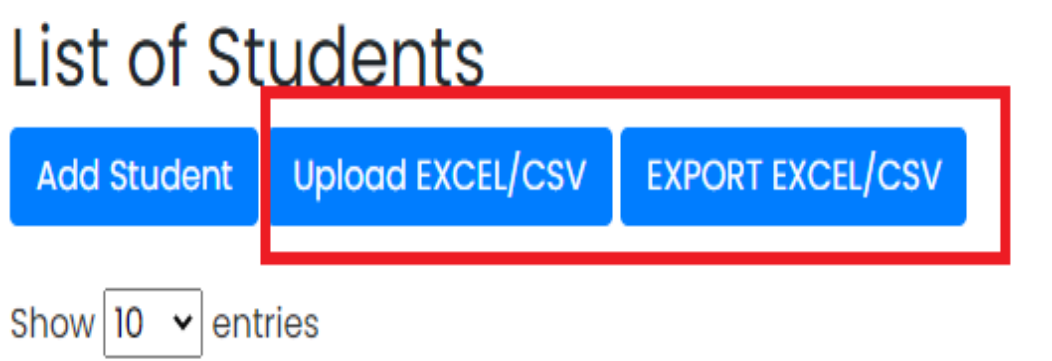

\subsubsection{Challenges Encountered In the Evaluation}

There were nine (9) out of fifteen (15) faculty members, nine (9) out of fifteen (15) IT experts, and thirty-six (36) out of sixty (60) students who noticed that there was no FAQs or Frequently Asked Question to the chatbot which is relevant in every social media messaging 
application. The same was added to the chatbot and opened a link to the answers to the frequently asked questions.

Figure 7

The LMS Administrator Account Adding FACQS Link Before and After Enhancement

Alpha Version

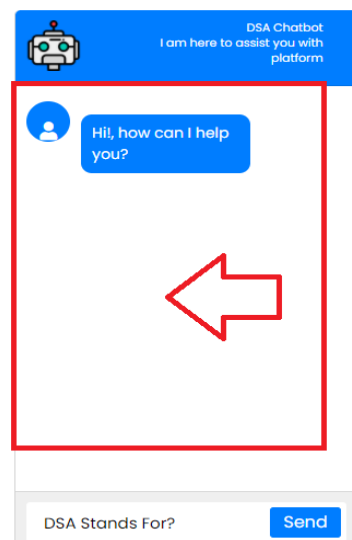

Beta Version

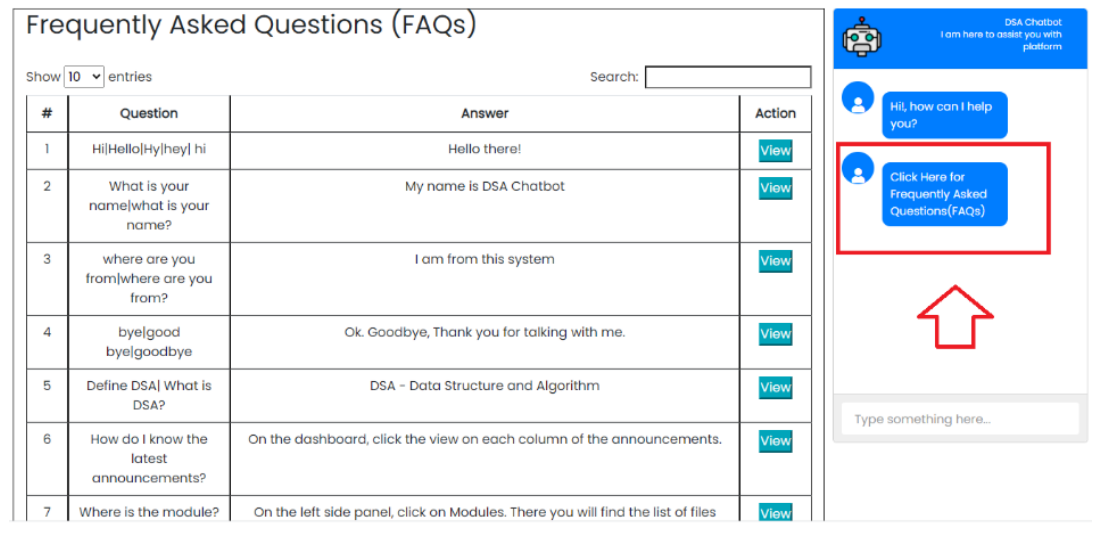

\subsubsection{Challenges encountered in the use of LMS}

Thirteen (13) out of fifteen (15) IT experts and ten (10) out of fifteen (15) faculty members said that it is very important to have backup features which is the standard in any existing system.

Figure 8

The LMS Administrator Account Backup Features Before and After Enhancement Alpha Version Beta Version

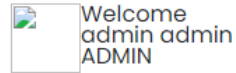
admin admin

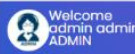

\begin{tabular}{|l|}
\hline Dashboard \\
\hline Teachers \\
\hline Students \\
\hline Chatbot \\
\hline Messages \\
\hline Logout \\
\hline
\end{tabular}

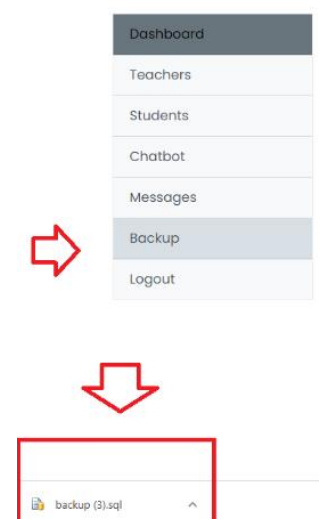


Moreover, fifty (50) out of sixty (60) students suggested to have a notifications icon for messaging. The inbox button or notification message button was added to the right corner of the header to be notified of the latest message by the admin and teachers.

Figure 9

The LMS Student Account Adding Notifications Before and After Enhancement

\section{Alpha Version} 2. Welcome

Data Structure and Algorithm

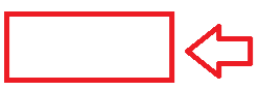

\section{Beta Version}

\section{Data Structures and Algorithms}

\subsubsection{Challenges encountered in the development of LMS implementation plan}

The system was implemented in the local server of a personal computer. Afterwards, a domain name was purchased at namesilo.com and a hosting plan at namecheap.com.

\section{Figure 10}

The LMS change of server from local server to a paid domain name and hosting site

\section{Alpha Version}

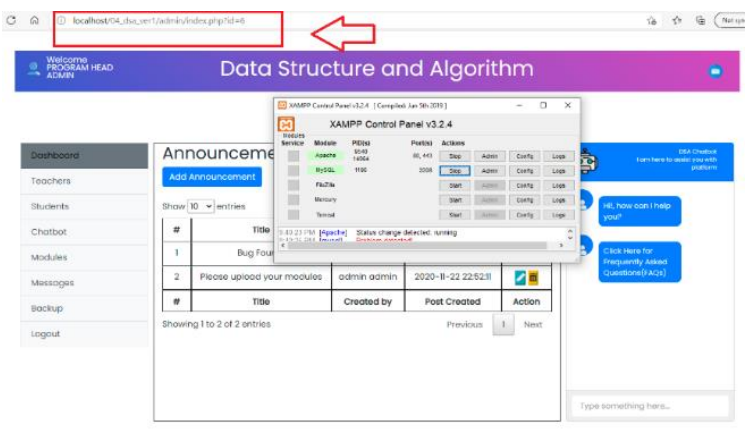

Beta Version

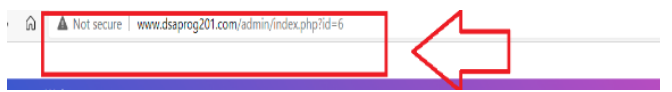




\subsection{LMS Implementation Plan}

Table 6

The School X Knowledge Transfer Plan

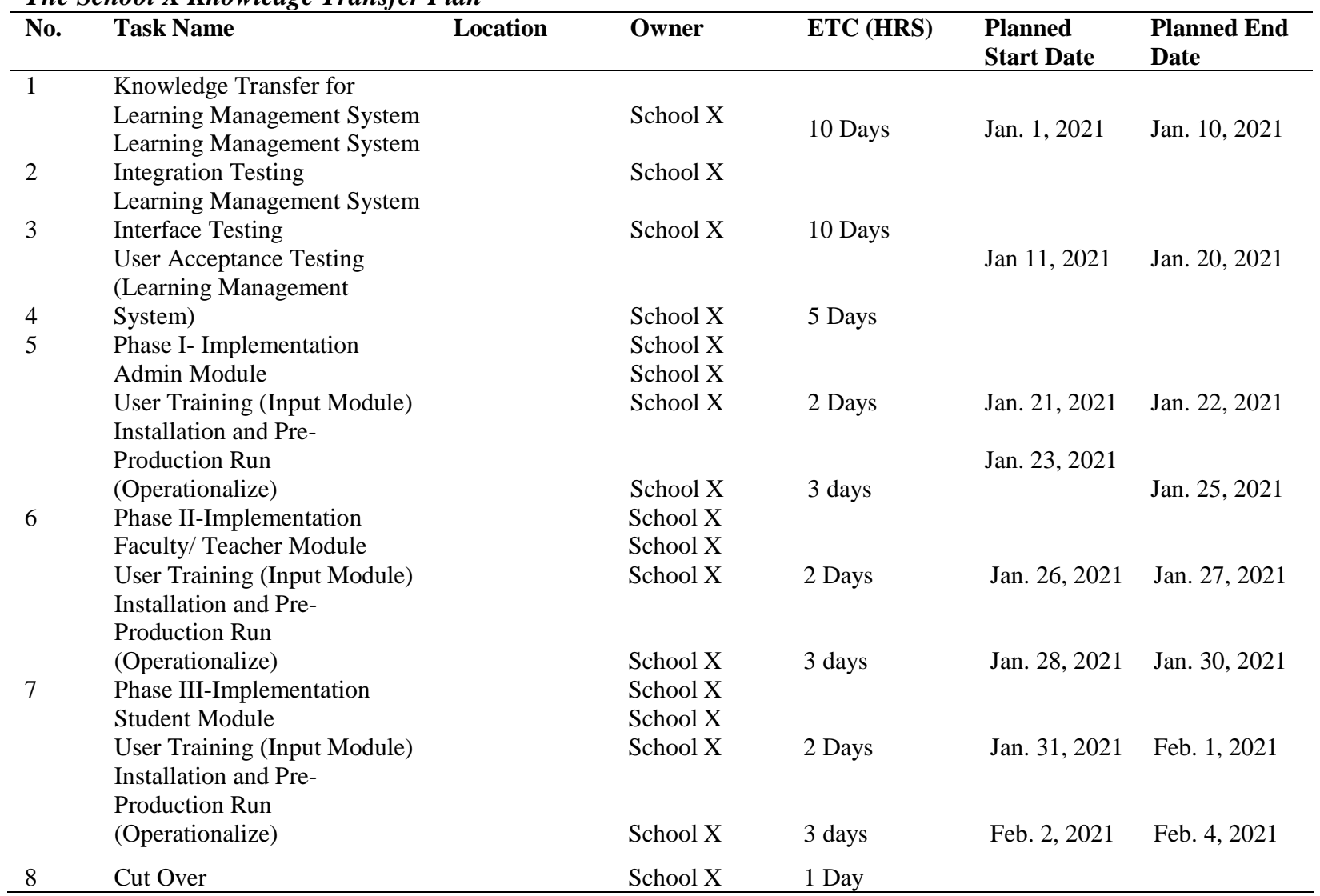

The implementation plan denotes the scheduled plan of instruction for each group of users. This also contains the matters discussed and training method used. As shown in Table 6, the project targets and the Gantt chart for the implementation of the program were illustrated.

\section{Conclusion}

The Waterfall Model was used in the development of LMS for Data Structures and Algorithms. This method encompassed several methods which are requirements analysis, system design, implementation, testing, deployment, and maintenance phases. The overall assessment indicated that the system is 'acceptable' as supported by the weighted means of 4.49 for the students, 4.43 for the faculty members, and 4.38 for the IT experts. Furthermore, 
the weighted means for each component are 4.51 for functionality, 4.38 for performance, 4.45 for usability, and 4.39 for reliability. These numerical evidence prove that the LMS for Data Structures and Algorithms serves its purpose and greatly benefits the end users especially in terms of functionality, performance, usability, and reliability in accordance with the standards of ISO 25010. Meanwhile, the ANOVA showed no significant difference in the LMS evaluation of the three groups of respondents in terms of functional suitability, performance efficiency, usability, and reliability. Therefore, the null hypothesis is accepted.

An implementation plan was also developed for the use of the LMS. It shows comprehensive procedures that elucidate the distinct functionalities of the system. A Gantt chart was created to have an idea of the timeline for the implementation. The methods in the user manual have been evaluated and tested to facilitate the understanding of the detailed usage of the LMS.

\section{References}

Abdulazeez, A. and Zeebaree, S. (2018). Design and implementation of electronic learning system for Duhok Polytechnic University. Academic Journal of Nawroz University. 7(3), pp. 249-258.

Aguirre, A., Villareal-Freire, A.,, Gil, R., and Collazos, C. (2017). Extending the concept of user satisfaction in e-learning systems from ISO/IEC 25010. Conference Paper in Lecture Notes in Computer Science. pp. 167-179.

Al-Samarraie, H. and Saeed, N. (2018). A systematic review of cloud computing tools for collaborative learning: Opportunities and challenges to the blended-learning environment. Computers \& Education. 124, pp. 77-91.

Allison, D.A. (2011). Chatbots in the library: is it time? Faculty Publications, UNL Libraries. https://digitalcommons.unl.edu/libraryscience/280

Alshorman, A. and Bawaneh, A. (2018). Attitudes of faculty members and students towards the use of the learning management system in teaching and learning. The Turkish Online Journal of Educational Technology. 17(3), pp. 1-15. 
Andersson, T. (2019). Case study on an implementation of an LMS and its perceived effects on teachers. Master Thesis in Informatics. Linnaeus University.

Arcand, K. (2017). Can chatbots fully replace humans? Not yet. Retrieved from https://www.destinationcrm.com/Articles/Columns-Departments/CustomerExperience/Can-Chatbots-Fully-Replace-Humans-Not-Yet-118196.aspx

Banimahendra, R. and Santoso, H. (2017). Implementation and evaluation of LMS mobile application: SCeLE mobile based on user-centered design. Journal of Physics Conference Series 978.

Barjtya, S., Sharma, A., Rani, U. (2017). A detailed study of Software Development Life Cycle (SDLC) models. International Journal of Engineering And Computer Science. 6(7), pp. 22097-22100

Brown, N., Kölling, M., Crick, T., Jones, S. P., Humphreys, S., \& Sentance, S. (2013). Bringing computer science back into schools: Lessons from the UK. Proceedings of the 44th ACM Technical Symposium on Computer Science Education (SIGCSE 2013), pp. 269-274.

Changwong, K., Sukkamart, A., and Sisan, B. (2018). Critical thinking skill development: Analysis of a new learning management model for Thai high schools. Journal of International Studies. 11(2), pp. 37-48.

Clark, D. (2018). The fallacy of "robot" teachers. Donald Clark Plan B. Retrieved from: https://donaldclarkplanb.blogspot.com/search?q=10+uses+for+Chatbots+in+1 earning+(with+examples)

Davidovitch, N. and Belichenko, M. (2016). Developmental and implementation challenges of e-learning management systems in higher education. Canadian Center of Science and Education. 6(4), pp. 170-180.

Fadhel, I., Idrus, S., Abdullah, M., Ibrahim, A., Omar, M., and Saad, S. (2019). Nias-Mukalla web based systems success measurement and students satisfaction evaluation based on security factor of systems quality engineering theory (ISO 25010) and other factors. Independent Journal Of Management \& Production. 10(6), pp. 2102-2123. 
Futurizable (2017). Estado del arte en el desarrollo de chatbots a nivel mundial. Futurizable. Retrieved from: https://futurizable.com/chatbot

Ghilay, Y. (2019). Effectiveness of learning management systems in higher education: Views of lecturers with different levels of activity in LMSs. Journal of Online Higher Education. 3(2). pp 29-50

Gomez, J. (2015). Higher education faculty use of a learning management system in face-toface classes. California State University.

Holak, B. (2018). Who's talking? Conversational agent vs. chatbot vs. virtual assistant. TechTarget. Retrieved from: https://searchcio.techtarget.com/feature/Whos-talkingConversationalagent- vs-chatbot-vs-virtual-assistant

Holmes, K. and Prieto-Rodriguez, E. (2018). Student and staff perceptions of a learning management system for blended learning in teacher education. Australian Journal of Teacher Education, 43(3).

ISO 25000. (2020). ISO/IEC 25010. https://iso25000.com/index.php/en/iso-25000standards/iso-25010

Karunaratne, T., Zhemchugova, H., Byungura, J., and Olsson, U. (2019). Towards an agilebased process model for effective teacher training on LMS. 18th European Conference on e-Learning.

Kocaleva, M., Stojanovic, I., and Zdravev, Z. (2015). Model of e-learning acceptance and use for teaching staff in higher education institutions. International Journal of Modern Education and Computer Science. 4, pp. 23-31.

Krouska, A., Troussas, C., Virvou, M. (2019). A literature review of social networkingbased learning systems using a novel ISO-based framework. Intelligent Decision Technologies, Vol. 13, no. 1, pp. 23-39

Lokare, V., Jadhav, P. (2016). A holistic approach for teaching Data Structure Course in the Department of Information Technology. Journal of Engineering Education Transformations, Volume, No, Month 2016, ISSN 2349-2473, eISSN 2394-1707. 
Malik, M., Abid, F., Kalaichelvi, R., and Bhatti, Z. (2018). Challenges of computer science and it in teaching-learning in Saudi Arabia. Sukkur IBA Journal of Computing and Mathematical Sciences. 2 (1), pp. 29-35.

Muhardi, M., Gunawan, S. I., Irawan, Y., \& Devis, Y. (2020). Design Of web based LMS (Learning Management System) in SMAN 1 Kampar Kiri Hilir. Journal of Applied Engineering and Technological Science (JAETS), 1(2), 70-76.

Ouadoud, M., Chkouri, M., Nejjari, A. (2018). Learning management system and the underlying learning theories: Towards a new modeling of an LMS. International Journal of Information Science \& Technology. 2(1), pp. 25-33.

Pradana, A., Goh, O. S., \& Kumar, Y. J. (2018). Intelligent conversational bot for interactive marketing. Journal of Telecommunication, Electronic, and Computer Engineering, 10, pp. 1-7.

Rhode, J., Richter, S., Gowen, P., Miller, T., \& Wills, C. (2017). Understanding faculty use of the learning management system. Online Learning, 21(3), pp. 68-86.

Rubin, M. (2013). The effectiveness of live-coding to teach introductory programming. In: Proceeding of the 44th ACM Technical Symposium on Computer Science Education. SIGCSE '13. New York, NY, USA: ACM. pp. 651-656.

Sentance, S., Csizmadia, A. (2017). Computing in the curriculum: Challenges and strategies from a teacher's perspective. Educ Inf Technol 22:469-495. DOI 10.1007/s10639016-9482-0

Shukla, V., Verma, A. (2019). Enhancing LMS experience through AIML base and retrieval base chatbot using $R$ language. 2019 International Conference on Automation, Computational and Technology Management (ICACTM).

Tarus, J., Gichoya, D. \& Muumbo, A. (2015). Challenges of implementing e-learning in Kenya: A case of Kenyan public universities. International Review of Research in Open and Distributed Learning, 16(1), 120-141. 
International Journal of Science, Technology, Engineering and Mathematics, Volume 2 Issue 3

Thompson, D., \& Bell, T. (2013). Adoption of new computer science high school standards by New Zealand teachers. ACM.

Wang, P. (2019). On defining artificial intelligence. Journal of Artificial General Intelligence. 10(2). pp 1-37.

Zydney, J. M. and Warner, Z. (2016). Mobile apps for science learning: review of research. Computers and Education, vol. 94, pp. 1-17. 